Abstracta Iranica Abstracta Iranica

Revue bibliographique pour le domaine irano-aryen

Volume 42-43 | 2021

Comptes rendus des publications de 2019-2020

\title{
Mohammad Ali Amir-Moezzi. Ali, le secret bien gardé. Figures du premier Maître en spiritualité shi'ite
}

\section{Pierre Lory}

\section{(2) OpenEdition}

1 Journals

\section{Édition électronique}

URL : https://journals.openedition.org/abstractairanica/54272

DOI : 10.4000/abstractairanica.54272

ISSN : 1961-960X

Éditeur :

CNRS (UMR 7528 Mondes iraniens et indiens), Éditions de l'IFRI

Référence électronique

Pierre Lory, «Mohammad Ali Amir-Moezzi. Ali, le secret bien gardé. Figures du premier Maitre en spiritualité shiïte », Abstracta Iranica [En ligne], Volume 42-43 | 2021, document 3, mis en ligne le 30 décembre 2021, consulté le 25 décembre 2022. URL : http://journals.openedition.org/ abstractairanica/54272 ; DOI : https://doi.org/10.4000/abstractairanica.54272

Ce document a été généré automatiquement le 25 décembre 2022.

Tous droits réservés 


\title{
Mohammad Ali Amir-Moezzi. Ali, le secret bien gardé. Figures du premier Maître en spiritualité shi'ite
}

\author{
Pierre Lory
}

\section{RÉFÉRENCE}

Mohammad Ali Amir-Moezzi. Ali, le secret bien gardé. Figures du premier Maître en spiritualité shi'ite. Avec des contributions de : Orkhan Mir-Kasimov et Mathieu Terrier. Paris : CNRS Editions, 2020, 470 p., ISBN 978-2-271-12497-5

Dernière parution d'un imposante suite de recherches de l'A. sur le shi'isme imamite ancien, le présent volume présente un recueil de contributions ayant en commun, non pas l'impossible objectif de tracer un portrait « historique » de 'Alī, mais de « faire une histoire des diverses représentations de 'Alī» (p.16) durant la période ancienne. Un premier chapitre, "'Alī et le Coran", rappelle le rôle attribué à 'Alī par les auteurs chiites comme principal herméneute du Coran, mais aussi comme thème de nombreux versets censurés par la suite, qui auraient mentionné 'Alī et sa nature métaphysique. Le second chapitre revient sur la dimension eschatologique de la prédication muhammadienne. L'A. est d'avis que Muhammad et ses premiers adeptes pensaient la fin du monde imminente, que la figure de Sauveur/ Messie ne serait autre que Jésus (p. 83), et que le Christ revenu ou à revenir serait bien 'Alī. Plus tard, à l'époque omeyyade, une réécriture de l'histoire dans le sens d'une « démessianisation » et d'un refoulement de la mention de 'Alī aura lieu. L'idée que 'Alī aurait été une figure messianique complémentaire de Muhammad est développée ensuite, à propos de l'expression « dīn 'Alī». Puis plusieurs chapitres sont consacrés à la figure métaphysique de 'Alī et des Imams dans le shi'isme de tendance ésotérique; où l'on retrouve la doctrine déjà présente dans le Proche-Orient tardo-antique de l'Homme parfait. On notera aussi l'important développement sur la notion de dissimulation (kitmān, taqiyya). L'A. souligne que cette attitude obéit entre autres à des exigences spirituelles bien définies, 
et suggère qu'elle était liée aux nuances profondes apportées à l'idée de clôture de la prophétie. Puis un chapitre est consacré à la pensée de l'auteur duodécimain Rajab Bursī (fin $14^{\mathrm{e}}$ - début $15^{\mathrm{e}}$ siècles) et plus précisément à son commentaire de versets du Coran qui auraient visé 'Alī comme figure métaphysique. Enfin, une dernière étude nous présente l'art des petits portraits représentant 'Alī, seul ou accompagné de membres de sa famille, que l'on peut trouver en Iran et dans les milieux chiites de l'Inde, et qui servent à titre divers de supports de contemplation. L'Epilogue présente une dense synthèse des principales thèses défendues dans ce volume, notamment sur la brève période " proto-islamique » où les discours sur la figure de 'Alī furent l'enjeu de basculements doctrinaux décisifs pour l'ensemble des courants en islam.

Le volume est enrichi par deux fort intéressants textes mis en annexe. Le premier, dû à Orkhan Mir-Kasimov, offre un tableau du rôle de légitimation qu'on a fait jouer à 'Alī au cours des siècles dans les différentes régions du monde islamique en dehors des milieux strictement chiites, depuis le $13^{\mathrm{e}}$ siècle jusqu'à la période ottomane. Le second, de Mathieu Terrier, offre des considérations très référencées sur l'apparition de dits de 'Alī dans la littérature de sagesse (comme dans le Nahj al-balāgha), mais aussi, de façon souvent inattendue, dans les textes de falsafa proprement dite ou de l'ishrāq. Une copieuse bibliographie et un index complet clôturent ce volume riche et érudit.

\section{AUTEURS}

PIERRE LORY

Section des Sciences Religieuses, Paris 